\title{
Maintaining Dual Career Balance: A Scenario Perspective on Swedish University Student- Athletes" Experiences and Coping
}

\author{
Corresponding author: Lukas Linnér \\ E-mail: lukas.linner@hh.se \\ School of Health and Welfare \\ Halmstad University \\ Box 823, 301 18, Halmstad, Sweden
}

Lukas Linnér ${ }^{1}$, Natalia Stambulova ${ }^{1}$, \& Kristina Ziegert $^{1}$

${ }^{1}$ School of Health and Welfare, Halmstad University, Halmstad, Sweden

Abstract

A Dual Career (DC) scenario perspective was introduced in the European project "Gold in Education and Elite Sport" (GEES) and is characterized by integration of student-athletes' athletic and nonathletic demands into difficult situations or periods (i.e., scenarios) requiring coping efforts. In this study we consider balance as the primary challenge for student-athletes and set out to identify DC scenarios that influenced university student-athletes' optimal DC balance, and the factors involved in coping with such scenarios. We implemented a post-positivist qualitative design through semistructured interviews with six university student-athletes. Our thematic analysis generated seven DC scenarios, for example, A sport event coincides with exams, and Finalize degree project and continue to train and compete. The scenarios, their characteristics and student-athletes' corresponding coping are described. Based on the findings, we suggest an updated definition of DC scenarios and present their taxonomy, with four types of DC scenarios in which student-athletes' circumstances challenge them to (a) maintain sport and study, (b) maintain study, (c) maintain sport, and (d) maintain personal life. We discuss how these developments can be useful for DC research and practice.

Keywords: Balance, coping, dual career scenarios, taxonomy, and university.

Using the holistic developmental approach (Wylleman et al., 2013) as a guide, Dual Career (DC) research (Stambulova \& Wylleman, 2019; Stambulova et al., 2021) has revealed that student-athletes experience demands across athletic and non-athletic levels of development (Brown et al., 2015), and they have to balance their time and energy to fulfil their commitments in different life areas. In this study we consider the process of balancing the DC as the overarching challenge for student-athletes with an optimal DC balance meaning "a combination of sport and studies that helps student-athletes achieve their educational and athletic goals, live satisfying private lives and maintain their health and wellbeing" (Stambulova et al., 2015, p.12). We continue the work initiated in the Erasmus + Sports project - Gold in Education and Elite Sport (GEES) - in which DC scenarios were introduced as encapsulating the demands from different levels of studentathletes' development (Wylleman, et al., 2017). In this study we aimed to identify DC scenarios that influenced university student-athletes' DC balance and their coping with such scenarios.

From Demands Across Developmental Levels to DC Scenarios

DC research has expanded in Europe since the introduction of the European DC guidelines to safeguard athletes' development, health and wellbeing (EU Commission, 2012). Several studies have showed how the demands of pursuing a DC span across different developmental levels (Brown et al., 2015; Burlot et al., 2018; Cosh \& Tully, 2014; Debois et al., 2015; Tekavc et al., 2015; Stambulova et al., 2015), as suggested by the holistic athletic career model (Wylleman, 2019). Demands include athletic (e.g., to train and perform at a higher level, performance expectations and injury setbacks), academic (e.g., increased study requirements and independency), psychological (e.g., develop identity, maintain motivation, and take personal responsibility), psychosocial (e.g., less parental support, develop a new social network, and manage relationships), and financial (e.g., work to make ends meet). At the heart of the DC is also to manage the combination, that is, demands that in their nature are inbetween developmental levels, for example, when exams coincide with competitions. The GEES project (Wylleman et al., 2017) initiated a move from differentiating studentathletes' demands across levels of development to integrating them into DC scenarios (i.e., difficult situations or periods in the DC pathway). Seven DC scenarios were formulated based on previous research and practitioners' experiences from across the nine European countries (De Brandt, 2017). The scenarios included (in abbreviated form, see for example Wylleman et al., 2017, for full 
versions): Exams (i.e., exams conflict with a crucial competitive phase), Study plan (i.e., select a study plan to manage the integration of both sport and study), Miss days of study (i.e., The need to catch up missed days of study during/after a camp/competition.), Relocation (i.e., relocate for DC with less family support and a new social network), Injury (i.e., continue to study and compete while suffering from an injury), Social life (i.e., the DC makes it challenging to have a rich social life), and Financial (i.e., the need to generate an income to pursue the DC). The experience and coping with the DC scenarios were explored across the European countries in a sample of 859 studentathletes $\left(M^{a g e}=21.4, S D=2.2 ; 48 \%\right.$ male and $52 \%$ females) competing at national or international championship level (De Brandt, 2017). The scenarios the student-athletes had experienced the most were Social life, Miss days of study and Exams (Mrange $=87-79 \%)$. Least experienced were the Injury (57\%) and Financial (29\%) scenarios. The student-athletes reported an average-togood coping with the scenarios ( $M^{\text {range }}=3.21-4.22 ; S D^{\text {range }}$ $=.82-1.05)$, managing Relocation $(M=4.22 ; S D=.86)$ and Study plan $(M=3.74 ; S D=.82)$ the best, and least good with the Injury $(M=3.57 ; S D=.98)$ and Financial $(M$ $=3.21 ; S D=1.05$ ) scenarios (De Brandt, 2017).

\section{Student-Athletes' Coping Resources and Strategies} Student-athletes' personal resources and/or coping strategies have been associated with successful coping (Debois et al., 2015; Stambulova et al., 2015) and explored across several studies (e.g., Brown et al., 2015; Cosh \& Tully, 2014; MacNamara \& Collins, 2010). Personal resources, meaning intrinsic factors or strengths that facilitates coping, highlighted in the previous research include organizational and time-management skills, selfawareness, self-discipline, dedication, perseverance, and interpersonal skills. Key coping strategies, meaning what student-athletes do to cope, include being proactive and planning ahead (including time for recuperation), changing priorities, communicating with staff, and seeking social support (e.g., Brown et al., 2015). Student-athletes' coping resources and strategies have also been summarized into four DC competency-factors (De Brandt et al., 2018) including DC management (e.g., self-discipline, timemanagement, planning, and prioritizing), career planning (e.g., vision of where to go in life), emotional awareness (e.g., stress-management), and social intelligence and adaptability (e.g., ability to ask for help, and make and maintain relations). DC competences have also been explored in relation to DC scenarios. When asked to choose the most important DC competences for coping with various scenarios the student-athletes across De Brandt (2017) and Linnér et al. (2019) highlighted the competences as follows. For the Exam and Miss days of study scenarios student-athletes emphasized prioritizing, time management, self-discipline, a present focus, and willingness to make sacrifices. For the Social life scenario, they emphasized the ability to make and maintain social contacts, time management, and willingness to make sacrifices (De Brandt, 2017; Linnér et al., 2019).

Beyond personal resources, previous research has showed the importance for student-athletes to have a network of support, for example, family, coaches, teachers, peers and DC-support providers, that recognizes the demands of pursuing a DC and responds in an autonomysupportive way (providing guidance, advice, flexibility or emotional support; Defruyt, 2019; Knight et al., 2018). Student-athletes can also experience DC barriers, meaning internal or external factors that interfere with the coping process, including for example a lack of DC understanding and flexibility (Geraniosova \& Ronkainen, 2015), or a lack of time for social life, rest, and recovery (Kristiansen, 2017).

\section{The Swedish DC Context}

Organized DC support has existed in Sweden for adolescent athletes (aged 16-18) since the early 1970s. In recent years, the professional DC support has been expanded by establishing sports universities guided by the Swedish national guidelines for elite athletes' DCs (Swedish Sports Confederation, 2018). In essence, the guidelines promote that a sport university should: (a) provide flexible study tailored to student-athletes based on local regulations, (b) cooperate with sports federations or clubs to facilitate a good training environment, (c) facilitate student-athletes' lifestyle balance and coping with career transitions, (d) provide a DC-coordinator and DC support providers, typically working part-time to facilitate flexible study, DC-understanding among staff, and sports-study collaborations. All students receive a state-funded grant (plus optional loan) to support going to a university program/course of their choice. Student-athletes compete for their sport clubs, and in their education follow the same study requirements as all other students. Currently, the DC system is under development and includes 20 Swedish universities and about 700 athletes, with some universities having many years of experience in supporting athletes' DCs, while others have only recently begun to develop such support (e.g., study flexibility).

\section{Objectives}

Previous research has suggested that beyond the scenarios developed in GEES (Wylleman et al., 2017) more scenarios may exist (Linnér et al., 2019). To forward our understanding into DC scenarios we combine it with optimal DC balance (Stambulova et al., 2015). Doing this, we aimed to (a) identify DC scenarios that influenced university student-athletes' optimal DC balance, and (b) explore the factors involved in the coping process (i.e., personal resources, support, barriers and coping strategies).

\section{Methods}

We position this study within post-positivism implying an ontological subtle realism and an objectivist epistemology. In this respect, we believe there is an external reality and meaning exists in objects that awaits discovery using appropriate methods (McGannon et al., 2021; Smith \& McGannon, 2017). A qualitative methodology was used to explore the experiences of the student-athletes through semi-structured interviews (Smith \& Sparkes, 2016) and a thematic data analysis (Braun et al., 2016).

\section{Participants}

Participants were selected based on a set of criteria. They had to be: (a) recipients of the Swedish Sports Confederation scholarship for combining high-performance sports and higher education (i.e., approximately $€ 4500$ awarded annually to 50 student-athletes), (b) alumni/bachelor graduates the current year to enable reflections throughout the full university DC, and (c) competing on at least the highest national level. Based on the selection criteria 14 individuals were identified via the information provided by the Swedish Sports Confederation. Of the 14, four were never reached, four declined due to a lack of time, and six agreed to participate. The participants were four females and two males with a mean age of 24.5 years $(S D=1.05)$, representing four universities across the country, and all bachelor graduates in Sport Sciences $(n=$ $3)$, Economy $(n=2)$, or Medicine $(n=1)$. The athletes were 
either world champions $(n=2)$, national champions ( $n=$ $2)$, or winners of senior national $(n=1)$ or European $(n=$ 1) competitions. Table 1 contains the participants' demographic information and assigned pseudonyms.

\section{Table 1}

Student-athletes' descriptive information

$\begin{array}{lllll}\begin{array}{l}\text { Parti- Gender Age Sport } \\ \text { cipant }\end{array} & \begin{array}{l}\text { Competi- } \\ \text { tive level }\end{array} & \begin{array}{l}\text { Study } \\ \text { pace } \\ (\%)\end{array}\end{array}$

\begin{tabular}{|c|c|c|c|c|c|}
\hline Eddie & Male & 25 & $\begin{array}{l}\text { Volley- } \\
\text { ball }\end{array}$ & $\begin{array}{l}\text { Interna- } \\
\text { tional, } \\
\text { senior }\end{array}$ & 100 \\
\hline Sofia & Female & 24 & $\begin{array}{l}\text { Martial } \\
\text { arts }\end{array}$ & $\begin{array}{l}\text { Interna- } \\
\text { tional, } \\
\text { senior }\end{array}$ & 100 \\
\hline Elsa & Female & 24 & Golf & $\begin{array}{l}\text { Interna- } \\
\text { tional, } \\
\text { senior }\end{array}$ & $\begin{array}{l}75 \\
(50- \\
100)\end{array}$ \\
\hline Jenny & Female & 23 & Golf & $\begin{array}{l}\text { National, } \\
\text { senior }\end{array}$ & $\begin{array}{l}75 \\
(50- \\
100)\end{array}$ \\
\hline Sandra & Female & 26 & $\begin{array}{l}\text { Eques- } \\
\text { trian } \\
\text { sport }\end{array}$ & $\begin{array}{l}\text { Interna- } \\
\text { tional, } \\
\text { senior }\end{array}$ & 100 \\
\hline John & Male & 25 & $\begin{array}{l}\text { Orien- } \\
\text { teering }\end{array}$ & $\begin{array}{l}\text { Interna- } \\
\text { tional, } \\
\text { senior }\end{array}$ & $\begin{array}{l}50 \\
(50- \\
100)\end{array}$ \\
\hline
\end{tabular}

Note: *The most common study pace is provided and when applicable with the range of study pace in parenthesis.

\section{Data Collection: Procedure, Ethics, and Interview} Guide

The study followed national ethical standards and was approved by an institutional ethics committee. The Swedish Sports Confederation provided a list of recipients of the DC scholarship, from which participants were selected, and then contacted and informed about the study by phone. Upon interest to take part an information letter outlining the study aim, procedure, and ethics (confidentiality, voluntary participation and right to withdraw) was sent by email and participants confirmed their participation in a returning email. At the start of the interview, information was repeated, and the participants signed an informed consent.

The semi-structured interviews (Smith \& Sparkes, 2016) consisted of five parts. First, participants were asked to share about themselves, their background and preuniversity DC experiences. In the second part, participants were provided with a blank two-page template of a DC profile. The profile had two major parts. A horizontal line at the mid-bottom and a percentage scale $(0-100)$ on the lefthand side. Participants were asked to indicate on the line their admission to university (to the far left) and graduation/today (to the far right) making a timeline. They then illustrated the dynamics in their DC lifestyle by indicating their perceived dedication of time and effort into their sports, studies and private/social life along the timeline using the percentage scale, for example, $50 \%$ of time towards sports, $30 \%$ towards studies, and $20 \%$ towards private/social life at a given time. In part three, participants were asked to review their profile, as a way of recollecting their experience, and identify difficult situations/periods across sports, studies and private/social life that had affected their DC balance and mark them on their timeline with a brief explanation. In part four, participants were asked to share about their DC balance in relation to their profile (e.g., Please, can you briefly share your way from the start-until-today in how you have balanced your DC and what you have marked on your timeline?). Finally, in part five and in relation to identified situations/periods, participants were asked to share what was challenging and how they had coped (e.g., Please describe the situation/period? How did you manage? What made it easier or more difficult to cope?). Interviews were 118-179 minutes long $(M=149.2 ; S D=28.6)$ and conducted by the first author at a time and place chosen by the participants (conference room at university or training centre, or in their home). A pilot interview was conducted to test the interview procedure. Minor changes were made to make the process of filling in the profile efficient to spend most time on participants sharing rather than illustrating their experiences.

\section{Data Analysis}

A small q coding reliability thematic analysis (Braun et al., 2016; Braun \& Clarke, 2019) was implemented in the following steps. In step one, the interviews were transcribed and read several times by the first author and shared with the co-authors for familiarization. In steps two and three, initial versions of scenarios were inductively identified followed by organizing the data in relation to each scenario. Scenarios in this respect acted as data domains (Braun \& Clarke, 2019) and within each scenario, meaning units where deductively categorized into high-order themes (i.e., personal resources, support, barriers, and coping strategies; inspired by the athletic career transition model, Stambulova, 2009) followed by inductively generating the lower-order themes, for example, themes within coping strategies. As new themes or scenarios were generated, previously coded materials were checked for signs of emergent scenarios or themes. The fourth and fifth steps involved going back and forth between meaning units, themes, and interview transcripts to refine and name all themes. The final step involved writing the study findings, including selecting and translating vivid examples of student-athletes' quotes to illustrate the findings.

The first author is a former student-athlete and was responsible for the analysis, and the paper is a part of his PhD project. The co-authors are PhD supervisors and for this study acted as "critical friends" by using their expertise in DC, health, and lifestyle research as well as qualitative methodology. With regards to rigor of this analysis grounded in post-positivism (McGannon et al., 2021) we would like to highlight that: (a) the interview transcripts were returned to participants who confirmed their experiences without any changes, (b) we did not independently code data to compare accuracy, rather throughout all steps of the analysis we engaged in critical discussions about coding, analytical choices, and interpretations to come to a mutual understanding and agreement about the accuracy of the findings. Central to this process was all the co-authors' challenging interpretations and providing insights, and (c) to enhance trustworthiness, the findings were shared with three participants to establish the degree to which our findings resonated with them. The scenarios and student-athletes coping were considered accurate with student-athletes saying: "it's very accurate to my experience" (Elsa) and "it 
matches my experience of combining sport and study" (John).

\section{Results}

The findings are summarized in Table 2, outlining seven scenarios with descriptive characteristics, and the studentathletes' associated personal resources, support, barriers encountered, and coping strategies implemented to maintain their DC balance. Below we describe each scenario and how the student-athletes coped.

\section{Integrate Sport and Study on an Everyday Basis} Sandra summarized the experience of integrating training and lectures on an everyday basis saying: "there are always things that coincide [during the day]. I usually say that everyone struggles with their life puzzle, but I have my Rubik's cube to solve every day". Sofia described a typical day illustrating the dynamic shifts in daily life: You leave home maybe at eight-nine, go to a lecture, then eat lunch that you brought from home. If you have a longer lunch, then maybe you have time for lunch and a workout, or you train early in the morning before school. After lunch you study, sometimes you go home, or you go straight from school to training. Maybe you have a little extra time there to study while waiting. After training you quickly jump into the shower to catch the early buss home saving ten minutes and come home around nine-nine thirty, eat some dinner, sleep, and then you just start all over again.

The quote above illustrates how the participants solved their everyday life by being organized, time-efficient and disciplined. The student-athletes emphasized these personal resources and their experience of the DC lifestyle: "I didn't feel it was hard because I was used to that way of living since high school" (Eddie). Key to coping with the dynamic shifts was also being able to adjust to the circumstances of the day. This is visible for example in how Sofia adjusted the planning and trained during lunch or in the morning depending on the study schedule. Sandra, whose training included riding horses several times per day, reflected on DC experience and adaptability:

From a young age [and through DC at high school] I've been use to a high tempo with different things happening and many unplanned things happening with the horses, so it wasn't a big change in how to make the everyday work [at university] ... as I've been trained in making quick decisions, prioritize and change plan very quickly.

The student-athletes' everyday life was facilitated by their family or partner who provided practical support when possible: "they help the best they can fixing things so that I am relieved in some areas" (Sandra). It was mainly about relieving the student-athletes of everyday routines like taking care of horses or cooking to facilitate the day: "If I needed food and didn't have it with me I could go to my parents who lived close to where I trained" (Sofia). Other supportive aspects for their everyday integration included proximity of university, training facility and housing and storing some personal equipment, for example, a towel at the training facility which reduced what to carry around at university all day.

\section{A Sport Event Coincides with Exams}

All the participants experienced the scenario of sport and study commitments coinciding in time, with games, competitions, championships, playoffs, or camps coinciding with exams including compulsory tasks/labs with mandatory attendance. John explains: "when you needed to be away on camp or competition you missed a lot in school, needing to do supplementary assignments for missing something mandatory, or just exams that could not be moved, and such clashes appeared quite frequently".

The student-athletes were motivated for both sport and study: "Sport was super-fun and it was so much fun studying at university" (Eddie). They had a high need for achievement and expectations on themselves to perform: "I am performance-oriented in everything I do" (Sandra). In trying to cope with the scenario, the student-athletes experienced a lack of understanding from their teachers as the main barrier and acknowledged that flexibility was person-bund: "the understanding that you don't try to dodge things, but that you try to combine these two things in a good way and if it's possible to facilitate in some way, that has varied a lot among teachers" (John). Communicate with teachers in advance was important, but more difficult initially due to student-athletes not knowing their rights or responsibilities: "It was difficult to know what I could say and not, what to push for, or how open I was to be about absence... I learned a kind of pattern in what worked and tried to work from there" (John). The lack of understanding, and that advertised support often did not match actual support, left some of the participants not asking their teachers for help. The student-athletes instead sought support and advice from their family or partner: "I've always been able to talk with my parents about everything... and [get advice] on how to act and what to put aside and what to do right now". Sofia, Elsa and Jenny studied in programs with athlete-peers and emphasized the athlete-classmates as a resource in sharing notes, picking up handouts when away, or synchronizing group work: "we had each other and been able to help each other" (Jenny). Some student-athletes emphasized the support from coaches which could be as simple as: "We just talk about the situation [i.e., sport and study coinciding]. I say what I plan to do and then the coach provides some suggestions and then everything feels better" (Elsa).

The participants acknowledged that they had "reached a level where you need to think in advance about how to plan everything and make it come together" (John), but when commitments coincided "one had to prioritize" (Sandra). Without flexibility from their teachers the student-athletes adapted and created their own flexibility, which almost exclusively involved prioritizing sports and postponing study, as illustrated by John and Sandra: "In the end I had to be flexible instead, if I cannot attend or hand in that assignment I will do the supplementary task instead, and solve it my way" (John) and "most of the time I postponed the exams because I could take them later [at a retake occasion]" (Sandra). Doing supplementary assignments was often perceived as a punishment and became a barrier in the coping process: "It's so much extra work [writing the assignments] than attending those sessions, so having prioritized sport we then worked uphill with the studies" (Jenny). Elsa, Jenny and John periodically studied at a reduced pace which "facilitated some travel, planning and when to be away on camps... and above all, the recovery" (John).

As the significance of the sport event increased with more training before/during important championships or playoffs, the participants found it more difficult to cope. Being motivated for both sport and study and wanting to do their best in both, the student-athletes responded with more discipline, time management, and determination, as illustrated by Eddie when having an important exam 
directly after the European Championship-qualifying tournament:

I had no spare time, the only thing I did was train and study. I practiced in the morning, studied, then lunch, then studied, then afternoon training and then study in the evening, and it was like that all the time, also during matchdays, because it was full focus, I was coming home to nail that exam while still performing in the games.

\section{Maintain Studies when Away for Camps or \\ Competitions}

Being absent from university did not always include missing exams, but still involved keeping up with study to not fall behind. The scenario of maintaining study while being away was highlighted by Sofia and Eddie whose coping efforts involved planning in advance and communicating with teachers: "You leave maybe Thursday or Friday [for a weekend competition] and then you don't miss that much. You try to understand what you will miss so that you can plan from there and talk to the teacher before" (Sofia). Being away the student-athletes made use of their time by being disciplined: "We flew quite often, so you sat at the airport or in the plane studying and when it wasn't focus on the competition you were in the hotel room studying" (Sofia) and "I remember every bus trip with the team sitting with the course book ploughing through pages" (Eddie). Having access to study materials online or support from classmates picking up handouts helped. Yet, being away still meant they missed learning opportunities which was perceived as the main barrier: "It's sad that you miss lectures because what the teachers say can be better than what is written in the book" (Sofia).

\section{Finalize Degree Project and Continue to Train and Compete}

Jenny, Eddie, Elsa and Sofia emphasized the scenario of writing their independent degree project while maintaining to train and compete. The scenario evoked an imbalance based on an increased workload in study making it challenging to manage: "it was a lot of studying compared to any time before. [Having] both sport and this amount of study just didn't add up" (Elsa) and "it was extreme time pressure, just sport and writing mattered...it felt like we constantly had time against us" (Jenny). As Eddie concluded: "I never want to do that again, it was probably one of the toughest things I've done". The student-athletes acknowledged that they needed to prioritize study but struggled to reduce their sports load. Some due to their sports schedule having, for example, pre-booked competitions or games, and others due to an internal barrier of accepting less focus on sport: "I didn't like to cut down on sports because of study, I wanted to prioritize sports" (Jenny). The student-athletes were motivated for both sport and study and had an ambition to achieve. With the high combined workload, they gave $100 \%$ to cope. The tendency to "put your head down and push forward" (Eddie) was accompanied by setting aside social life or neglect sleep to gain time, as explained by Jenny:

I reduced the amount of sleep quite a lot. I did it to cope, but it affected me also afterwards. Sport went well here so then it didn't feel so hard, but right after you felt you had sacrificed a lot and pushed yourself extremely hard.

Being determined and good at organization and time management the student-athletes pushed themselves to maximize their use of time, as exemplified by Eddie: "I was in the bus on the way to a game and interviewed one of the participants [of my study project]... He was very busy, and
I couldn't move my game... it worked, but it was very stressful". To not waste valuable time, they used their ability to be disciplined and focused on the task at hand: "I did my workout and the things I needed to do, then back home and write" (Jenny).

The student-athletes did not report much help from the university or their sport. Their main coping strategy was to write the thesis with an allied student-athlete or partner who understood and supported their situation: "I wrote with my partner. I had games and training throughout the week and could not write with anyone else to pull away like that all the time, it's not possible without [understanding]" (Eddie). In contrast to giving $100 \%$, Sofia planned in advance to balance the workload but struggled with her writing partner:

When you write with someone else you need to adjust to their schedule. I wanted to plan [our work], but she was out in the last second... A friend in class became like our mediator, we talk about it and although we didn't solve it completely because I'm not fully satisfied with what we wrote, we managed to pass [the course].

\section{A Need to Change Residence Coincides with a Performance Slump}

John experienced that circumstances in his personal life affected the DC balance when the need to change residence suddenly appeared while managing an ongoing performance slump:

Performance was going up and down and you start to think, should I do like this or that, while also having school which at that time you feel is just taking more time and more energy and then another thing comes, and you should look for housing at the same time, so you feel that, okay it's not exactly the housing I want to focus on now... and you get quite divided when things you need to do come together like that.

Having already a working alliance with a sport psychology consultant John sought help: "my biggest support here was my consultant, to discuss and... come to what's important to focus on, what I can do, and what's realistic in terms of performance but also besides sports to function and feel good". With the support of family and the consultant John coped by prioritizing, planning, setting goals and focus on the present:

I really had to structure and plan what I needed to do... like with the housing, trying to do one thing at a time and when that's done check it off and move on to practice, [being] clear towards yourself about when you do the one or the other.

Engage in a Romantic Relationship along with Sport and Study

The commitments in the DC coincided with a partner relationship for Eddie:

Everything happened at once, precisely everything... being the team captain I had to run to media interviews while at the same time play three games a week in the playoffs, study was there gnawing, and I had just met the girl I wanted to share my life with... It was $100 \%$ sports and $100 \%$ study, no but fifty-fifty, and then you throw in a lot of private life, so it's just that the day only had 24 hours that made it very stressful, with yet another thing in the life puzzle.

Eddie shared how the coach provided support: 
The coach recognized my stress and said 'Now you need to skip a training, or I take that interview, so you can focus on studies'. I never took time off from any training. But he was very supportive and always came and asked how I felt and things like that.

Rather than reducing the sport load and acting on the coach support, Eddie relied on himself and the coping strategies that had worked in the past, including giving $100 \%$, neglect sleep, focus on the present, and postpone study: "I took one week at a time and if it turned out that next week it's exam, then I skipped it and pushed it forward [to the retakes]...to free up time for sport and private life instead of school".

\section{Having a Social Life along with Sport and Study}

In their timelines the participants devoted the least time to private/social life and did not mention social life in the interviews very much. When prompted about this Jenny and Elsa said: "it's because it just doesn't exist time for everything" (Jenny) and "I tried to think about it but I don't think I have any social life" (Elsa).
Sofia, Elsa and Jenny (studying with other athletes) acknowledged that sports provided a social life: "I cover $m y$ needs for a social life with friends when I train and study" (Jenny), and that friends outside sports could lack an understanding: "You don't have the university life [like nonsport peers have], going to town, coffee with friends or party... and I'm fine with that, but I've been questioned by non-sports friends, how one can enjoy to live like this" (Jenny). Sofia, also struggling with time for social life, focused on seizing the opportunities: "You don't hang out with friends in the weekend very much, but when you do, you make sure it's quality time". To manage a social life along with the DC the participants highlighted the importance of being honest about their priorities and focus on the supportive friends, as illustrated by Sofia:

To friends who might say 'we never see each other, and you just prioritize sports' [it is important] to be straight, honest and say, well now my life is like this, I prioritize my training and you come after unfortunately... To socialize with people who support you.

Table 2

The scenarios and the student-athletes' related personal resources, support, barriers, and coping strategies

\begin{tabular}{llll}
\hline DC scenario & $\begin{array}{l}\text { Characteristics } \\
\text { of scenario }\end{array}$ & $\begin{array}{l}\text { Personal } \\
\text { resources }\end{array}$ & $\begin{array}{l}\text { Support } \\
\text { provided }\end{array}$ \\
\hline Integrate & Daily life & Organization and & Supportive \\
sport and & involving & time- & family/partner \\
study & dynamic shifts & management (6) & $(7)$ \\
on an & between sport & Experience of DC & Proximity of \\
everyday & and study & lifestyle (5) & university, \\
basis $(n=2)$ & & Adaptability (3) & training facility \\
& & Self-discipline (2) & and housing (2) \\
& & Decision making & Store \\
& & ability (1) & equipment at \\
& & Self-confidence & training facility \\
& & $(1)$ & $(1)$
\end{tabular}

\begin{tabular}{|c|c|}
\hline \multirow[t]{3}{*}{$\begin{array}{l}\text { A sport } \\
\text { event } \\
\text { coincides } \\
\text { with exams } \\
(n=6)\end{array}$} & $\begin{array}{l}\text { Coinciding } \\
\text { commitments } \\
\text { in sport and } \\
\text { study }\end{array}$ \\
\hline & $\begin{array}{l}\text { Absence from } \\
\text { study due to } \\
\text { sports }\end{array}$ \\
\hline & $\begin{array}{l}\text { The difficulty } \\
\text { increased with } \\
\text { significance of } \\
\text { sport event }\end{array}$ \\
\hline
\end{tabular}

Maintain

studies

when away

for camps or competitions $(n=2)$
Absence from study due to sports

No exams when away

Self-discipline (9) Supportive DC motivation (9) family/partner Organization and (7) timemanagement (7) Determination (7) High need for achievement (5) Adaptability (3) Reduced study pace (7) Supportive classmates (7) Supportive coach (3)

Organization and timemanagement (2) Self-discipline (2) Access to study materials online (1) Supportive classmates (1)

Barriers encountered (Internal/External)

Proximity of university, training facility and housing (1)

Fragmented schedule (1) Coping strategies implemented

\section{Adjust to} circumstances (3)

Prioritize (2)

Plan in advance (2)

Lack of understanding and flexibility from teachers (22)

Supplementary assignments feel like punishment (5) Unaware of rights and responsibilities as student-athlete (4) Perceived lack of time (4) High expectations on self (3)

Distance relationship/away

from partner (2)

Pre-competition anxiety (2)

Missed learning opportunity (2)
Postpone study/exams (16)

Plan in advance (10)

Prioritize (9)

Communicate with teachers (8)

Seek social support (4) Focus on present (4) Set aside private/social life (3) Learn from experience (1) Give $100 \%$ (1) 


\begin{tabular}{|c|c|c|}
\hline $\begin{array}{l}\text { Finalize } \\
\text { degree } \\
\text { project and } \\
\text { continue to } \\
\text { train and } \\
\text { compete } \\
(n=4)\end{array}$ & $\begin{array}{l}\text { Coinciding } \\
\text { commitments } \\
\text { in study and } \\
\text { sport } \\
\text { Increased } \\
\text { workload in } \\
\text { study with } \\
\text { maintained } \\
\text { workload in } \\
\text { sport }\end{array}$ & $\begin{array}{l}\text { Organization and } \\
\text { time- } \\
\text { management (5) } \\
\text { DC motivation (4) } \\
\text { Self-discipline (3) } \\
\text { Determination (2) } \\
\text { High need for } \\
\text { achievement (2) } \\
\text { Adaptability (1) }\end{array}$ \\
\hline
\end{tabular}

Understanding from thesis partner (5) Supportive classmate (2) Flexible supervisor (1) Supportive coach (1)
Perceived lack of time (6) Accept less focus on sport (6)

Unable to change sport schedule (2) Synchronize the work and schedule with thesis partner (2) Poor understanding from supervisors (1) Poor understanding from teammates (1)

Doubts (2)

Sport psychology

\begin{tabular}{|c|c|c|}
\hline $\begin{array}{l}\text { A need to } \\
\text { change } \\
\text { residence } \\
\text { coincides } \\
\text { with a } \\
\text { performance } \\
\text { slump }(n=1)\end{array}$ & $\begin{array}{l}\text { Coinciding } \\
\text { commitments } \\
\text { in sport, study } \\
\text { and personal } \\
\text { life }\end{array}$ & $\begin{array}{l}\text { Organization and } \\
\text { time- } \\
\text { management (1) } \\
\text { Communication } \\
\text { skills (1) } \\
\text { DC motivation (1) }\end{array}$ \\
\hline $\begin{array}{l}\text { Engage in a } \\
\text {-omantic } \\
\text { elationship } \\
\text { along with } \\
\text { sport and } \\
\text { study }(n=1)\end{array}$ & $\begin{array}{l}\text { Coinciding } \\
\text { commitments } \\
\text { in sport, study } \\
\text { and personal } \\
\text { life }\end{array}$ & $\begin{array}{l}\text { DC motivation (4) } \\
\text { High need for } \\
\text { achievement ( } 1 \text { ) } \\
\text { Organization and } \\
\text { time- } \\
\text { management (1) }\end{array}$ \\
\hline $\begin{array}{l}\text { Having a } \\
\text { social life } \\
\text { along with } \\
\text { sport and } \\
\text { study }(n=4)\end{array}$ & $\begin{array}{l}\text { High workload } \\
\text { in sport and } \\
\text { study makes } \\
\text { social life } \\
\text { limited }\end{array}$ & $\begin{array}{l}\text { Communication } \\
\text { skills (1) } \\
\text { Organization and } \\
\text { time- } \\
\text { management (1) } \\
\text { Independent } \\
\text { person (1) }\end{array}$ \\
\hline
\end{tabular}

consultant (2)

Supportive

family/partner (1)

$\begin{array}{ll}\text { Supportive } & \text { Perceived lack of time } \\ \text { coach (1) } & \text { (3) } \\ & \text { Media taking time (1) }\end{array}$

Social life through sports (5)

Lack of understanding
from friends (2)
Lack of
sleep/socializing too
much (1)

Give 100\% (4) Write thesis with an allied (4) Set aside private/social life (3) Maximize use of time (2) Neglect sleep (2) Rely on self (2) Focus on present (2) Plan in advance (1) Prioritize (1) Accept good enough grade (2)

\author{
Ask for help (2) \\ Prioritize (2) \\ Focus on present (2) \\ Plan in advance (1) \\ Goal setting (1)
}

\section{Postpone study/exams (6)}

Focus on present (3) Neglect sleep (1)

Rely on self (1)

Give $100 \%$ (1)

\section{Seize opportunity} when time allows (2) Focus on few but supportive friends (2) Be honest about priorities (1)

Note: Number in parentheses indicates the number of raw data quotes relevant to each theme.

\section{Discussion}

In this study we set out to identify DC scenarios that influenced university student-athletes' optimal DC balance and explored the factors involved in managing such scenarios. Doing this we continued to integrate rather than separate demands across student-athlete's levels of development by exploring DC scenarios as initiated in the GEES project (Wylleman et al., 2017). Below, we try to advance the understanding of DC scenarios in studentathletes' development by suggesting a taxonomy and updating the definition by conceptualizing DC scenarios as pre-transition situations.

We identified seven DC scenarios and their characteristics (see Table 2). Based on our findings we believe it is possible to classify the DC scenarios identified in our study and those suggested in GEES (Wylleman et al., 2017) into different types based on their core challenge. In Table 3 we suggest a taxonomy with four types of dynamic pre-transition situations in which student-athletes' circumstances challenge them to (a) maintain sport and study, (b) maintain study, (c) maintain sport, and (d) maintain personal life. As seen in Table 3, several scenarios identified in this study provide support for scenarios developed and explored in the GEES project and previous research, including for example, Exams and Social life (De Brandt, 2017; Linnér et al., 2019). Beyond those already identified, this study adds additional scenarios and scenario-types. Three scenarios from the GEES project are outside of the empirically updated definition of DC scenarios as suggested below. Although important for studentathletes, Injury and Relocation describes career transitions, and Study plan promotes more of an awareness and overall coping strategy of DC planning in advance.

Based on our findings we believe the definition of DC scenarios used in previous research, that is, difficult situations or periods in the DC pathway (De Brandt, 2017; Linnér et al., 2019) can be enriched. We suggest that DC scenarios are pre-transition situations constituting a combination of student-athletes' circumstances that compromises their DC balance. DC scenarios are characterized by coinciding commitments across developmental levels, and student-athletes' need personal resources, support, and coping strategies to maintain their optimal DC balance. Important to note is that optimal DC balance does not suggest an equilibrium or that studentathletes always should spend equal amount of time or effort on sport and study. DC balance is a dynamic state that from time to time, for example in the case of a DC scenario, requires consideration. Student-athletes should be observant of coinciding commitments to be able to make timely adjustments and cope with the related core challenge. DC scenarios and career transitions are both change-processes. Career transitions are turning phases in development that have the power to change an individuals' career trajectory (Stambulova et al., 2021). DC scenarios 
Table 3

A taxonomy of DC scenarios with associated examples of DC scenarios found in this study and in the GEES project

\begin{tabular}{llll}
\hline $\begin{array}{l}\text { Scenario-type } \\
\text { (core challenges) }\end{array}$ & Description of scenario-type & Scenarios from this study & Scenarios from GEES project \\
\hline $\begin{array}{l}\text { Maintain sport and } \\
\text { study }\end{array}$ & $\begin{array}{l}\text { Student-athletes' circum- } \\
\text { stances require several }\end{array}$ & $\begin{array}{l}\text { Integrate sport and study } \\
\text { on an everyday basis. }\end{array}$ & $\begin{array}{l}\text { The financial need to generate } \\
\text { an income to pursue the DC. }\end{array}$
\end{tabular}

Maintain study shifts in daily life.

Student-athletes' circumstances require prioritizing sport but also maintaining study.

Maintain sport

Maintain personal life
Student-athletes' circumstances require prioritizing study but also maintaining sport.

Student-athletes' circumstances require prioritizing sport and study but also maintaining personal life.
A sport event coincides with exams. Maintain studies when away for camps or competitions.

Finalize degree project and continue to train and compete.

Need to change residence. Engage in a romantic relationship.

Having a social life along with sport and study.
Exams conflict with a crucial competitive phase.

The need to catch up missed days of study after a camp/competition.

The DC makes it challenging to have a rich social life.

Note: Italics added in the GEES scenarios to link to corresponding scenarios as presented in the introduction.

are pre-transition situations as they cannot change the career trajectory but have the power to initiate (or delay) a career transition, for example, failure in coping with coinciding exams and competitions can initiate a transition leading to DC termination, or inability to combine sport and study with a satisfactory social life or romantic relationship might compromise psychosocial development. A DC scenario that is successfully managed means no transition is initiated and the student-athlete continues the DC pathway.

As for the student-athletes' coping across the DC scenarios, this study confirms previous research (Brown et al., 2015; De Brandt, 2017; Linnér et al., 2019) showing the usefulness of key personal resources (organization and time management, self-discipline, and motivation), coping strategies (planning in advance, prioritizing, and communicating with teachers), and support (DC understanding and advice from family, partner, peers and teachers). In similarity with previous research the most common barriers were lack of understanding and flexibility from teachers (e.g., Geraniosova \& Ronkainen, 2015), and that flexibility was person-bund. Set in the context of the Swedish DC system and that DC support is being developed across many universities (Swedish Sports Confederation, 2018) such a finding shows the necessity of continuing the work to secure flexibility and support for student-athletes. This study adds to the previous research by showing how the student-athletes compensated for the lack of flexibility with adaptability, determination and time management to create their own flexibility by prioritizing sport and postponing study. When the coping strategy of postponing study was not enough to solve the situation the studentathletes gave $100 \%$ to cope and experienced elevated stress. These findings emphasize the central role of flexibility in athletes' DCs, and the importance of flexibility from both study and sport to safeguard student-athletes' health and wellbeing (EU Commission, 2012). That is, provide a support provision that help student-athletes reach their sport and study goals, live a satisfactory private life, and maintain their health and wellbeing (Stambulova et al., 2015).
The Study Strength and Limitations,

Recommendations for Research and Practice

A strength of this study was the inclusion of studentathletes from a variety of sports at high-performance level, different universities, and study programs; providing a perspective across sport and study contexts yet limited to one country and with an emphasis on individual sports. We acknowledge that there might be a recall bias in reflecting about past experiences, but we believe this was outweighed by student-athletes' being recent graduates and having the ability to reflect upon the full university experience and put their experiences and scenarios into perspective. One key limitation potentially separating the participants from comparable student-athletes was their financial support through the DC scholarship, which could explain why there were no scenarios in our findings related to the studentathletes' financial situation.

DC researchers might consider continuing to integrate student-athletes' demands in DC scenarios by exploring different scenario-types as suggested by the taxonomy presented in this paper and by developing the taxonomy further. For examples, context-specific scenarios of the student-athletes can be considered. Based on our findings and the Swedish DC context, we see a benefit of future research with an emphasis on the maintaining sport, while prioritizing study, scenarios as our participants seemed to struggle more with this scenario type, for example, studying for an exam and maintaining training load. DC research in Sweden has also showed how studentathletes struggled with the Social life and Financial scenarios (Linnér et al., 2019) pointing towards the benefit of future research targeting the maintaining personal life scenarios, for example, maintaining a satisfactory social life along with investing in sport and study, and the maintaining sport and study scenarios, for example, reducing study pace meaning less study allowance and needing to balance sport and study with a spare-time job.

We recommend DC-practitioners to: (a) help student-athletes develop and maintain an optimal DC balance keeping in mind potential scenarios capable of compromising it, (b) in line with a whole person approach target how demands from different levels of student- 
athletes' development interplay and create DC scenarios, and (c) discuss different types of DC scenarios and corresponding coping with their student-athletes potentially using quotes from this study to stimulate awareness and reflections.
Acknowledgement

We would like to thank the participants for taking the time to share their experiences and the Swedish Sports Confederation and Anette Andreasson for organizational support.
Braun, V., \& Clarke, V. (2019). Reflecting on reflexive thematic analysis. Qualitative Research in Sport, Exercise and Health, 11, 589-597. https://doi.org/gf89jz

Braun, V., Clarke, V., \& Weate, P. (2016). Using thematic analysis in sport and exercise research. In B. Smith \& A. C. Sparkes (Eds.), Routledge handbook of qualitative research in sport and exercise (pp. 191-205). Routledge.

Brown, D. J., Fletcher, D., Henry, I., Borrie, A., Emmett, J., Buzza, A., \& Wombwell, S. (2015). A British university case study of the transitional experiences of student-athletes. Psychology of Sport and Exercise, 21, 78-90. https://doi.org/10.1016/j.psychsport.2015.04.002

Burlot, F., Richard, R., \& Joncheray, H. (2018). The life of highlevel athletes: The challenge of high performance against the time constraint. International Review for the Sociology of Sport, 53, 234-249. https://doi.org/10.1177/1012690216647196

Cosh, S., \& Tully, P. J. (2014). "All I have to do is pass": a discursive analysis of student-athletes' talk about prioritizing sport to the detriment of education to overcome stressors encountered in combining elite sport and tertiary education. Psychology of Sport and Exercise, $15,180-189$ https://doi.org/10.1016/j.psychsport.2013.10.015

Debois, N., Ledon, A., \& Wylleman, P. (2015). A lifespan perspective on the dual career of elite male athletes. Psychology of Sport and Exercise, 21, 15-26. https://doi.org/10.1016/j.psychsport.2014.07.011

De Brandt, K. (2017). A holistic perspective on student-athletes' dual career demands, competencies, and outcomes[Doctoral dissertation, Vrije Universiteit Brussel]. VUBPRESS.

De Brandt, K., Wylleman, P., Torregrossa, M., Schipper-van Veldhoven, N., Minelli, D., Defruyt, S., \& De Knop, P. (2018). Exploring the factor structure of the dual career competency questionnaire for athletes in European pupiland student-athletes. International Journal of Sport and Exercise Psychology. Advance Online Publication. https://doi.org/10.1080/1612197X.2018.1511619

Defruyt, S. (2019). Dual career support providers: Competencies, support strategies and education [Doctoral dissertation, Vrije Universiteit Brussel]. VUBPRESS.

European Commission. (2012). EU guidelines on dual careers of athletes: Recommended policy actions in support of dual careers in high performance sport. Retrieved from https://ec.europa.eu/assets/eac/sport/library/documents/ dual-career-guidelines-final_en.pdf

Geraniosova, K., \& Ronkainen, N. J. (2015). The experience of dual career through Slovak athletes' eyes. Physical Culture and Sport. Studies and Research, 65, 31-40. http://doi.org/10.1515/pcssr-2015-0005

Knight, C. J., Harwood, C. G., \& Sellars, P. A. (2018). Supporting adolescent athletes' dual careers: The role of an athlete's social support network. Psychology of Sport and Exercise, $38,137-147$ https://doi.org/10.1016/j.psychsport.2018.06.007

Kristiansen, E. (2017). Walking the line: How young athletes balance academic studies and sport in international competition. Sport in Society, 20,47-65. https://doi.org/10.1080/17430437.2015.1124563

Linnér, L., Stambulova, N., Lindahl, K., \& Wylleman, P. (2019). Swedish university student-athletes' dual career scenarios and competences. International Journal of Sport and Exercise Psychology. Advance online publication. https://doi.org/10.1080/1612197X.2019.1611898

MacNamara, A., \& Collins, D. (2010). The role of psychological characteristics in managing the transition to university. Psychology of Sport and Exercise, 11, 353-362. https://doi.org/10.1016/.j.psychsport.2010.04.003

McGannon, K. R., Smith, B., Kendellen, K., \& Gonsalves, C. A. (2021). Qualitative research in six sport and exercise psychology journals between 2010 and 2017: An updated and expanded review of trends and interpretations. International Journal of Sport and Exercise Psychology, 19, 359-379.

https://doi.org/10.1080/1612197X.2019.1655779

Smith, B., \& McGannon, K. R. (2017). Developing rigor in qualitative research: Problems and opportunities within sport and exercise psychology. International Review of Sport and Exercise Psychology, 11, 101-121. https://doi.org/10.1080/1750984X.2017.1317357

Smith, B., \& Sparkes, A. C. (2016). Interviews: Qualitative interviewing in the sport and exercise sciences. In B. Smith, \& A. C. Sparkes (Eds.), Routledge handbook of qualitative research in sport and exercise (pp. 103-123). Routledge.

Stambulova, N. (2009). Talent development in sport: A career transitions perspective. In E. Tsung-Min Hung, R. Lidor, and D. Hackfort (Eds.), Psychology of sport excellence (pp. 63-74). Fitness Information Technology.

Stambulova, N., Engström, C., Franck, A., Linnér, L., \& Lindahl, K. (2015). Searching for an optimal balance: Dual career experiences of Swedish adolescent athletes. Psychology of Sport and Exercise, 21, 4-14. https://doi.org/10.1016/j.psychsport.2014.08.009

Stambulova, N., Ryba, T., \& Henriksen, K. (2021). Career development and transitions of athletes: the International Society of Sport Psychology position stand revisited. International Journal of Sport and Exercise Psychology, 19 524-550. https://doi.org/10.1080/1612197X.2020.1737836

Stambulova, N., \& Wylleman, P. (2019). Psychology of athletes' dual careers: A state-of the art critical review of the European discourse. Psychology of Sport and Exercise, 42, 74-88. https://doi.org/10.1016/i.psychsport.2018.11.013

Swedish Sports Confederation. (2018). Swedish national guidelines for elite athletes' dual careers. Recommended actions for the combination of high-performance sports and university education at Swedish national sports universities (RIUs) and elite sports-friendly universities (EVLS). The Swedish Sports Confederation. https://www.rf.se/contentassets/12b2b3db9b88485e847b 3c7771d21b3d/swedish-national-guidelines-dualcareers.pdf

Tekavc, J., Wylleman, P., \& Cecić Erpič, S. (2015). Perceptions of dual career development among elite level swimmers and basketball players. Psychology of Sport and Exercise, 21, 27-41. https://doi.org/10.1016/j.psychsport.2015.03.002

Wylleman, P. (2019). A developmental and holistic perspective on transitioning out of elite sport. In M. H. Anshel (Ed.), APA Handbook of Sport and Exercise Psychology: Vol. 1. Sport Psychology (pp. 201-216). American Psychological Association.

Wylleman, P., De Brandt, K., \& Defruyt, S. (2017). GEES handbook for dual career support providers. https://kics.sport.vlaanderen/topsport/Documents/170301 GEES Handbook for dual career support providers.pdf

Wylleman, P., Reints, A., \& De Knop, P. (2013). A developmental and holistic perspective on athletic career development. In P. Sotiaradou, \& V. De Bosscher (Eds.), Managing high performance sport (pp. 159-182). Routledge. 